\title{
PROPOSTA DE DEFINIÇÃO DE INDICADORES PARA A OUVIDORIA DA ARSAE-MG
}

\author{
Katherynne Michelynne Cruz Rodrigues ${ }^{1}$
}

\begin{abstract}
Resumo
A Ouvidoria Pública é um espaço no qual o cidadão pode levar ao conhecimento da Administração Pública as suas necessidades e reclamações, auxiliando na busca da melhoria dos serviços prestados e exercendo seu direito à cidadania. $\mathrm{O}$ trabalho efetuado pelas Ouvidorias deve ser mensurado a fim de proporcionar eficácia, visando a prestação do serviço com melhor qualidade. Para tanto, o presente trabalho sugere três indicadores passíveis de uso em Ouvidorias Públicas: Índice de resolubilidade, Índice de atendimento aos prazos de resposta e Prazo médio de resposta das demandas. Para o cálculo dos indicadores usou-se o banco de dados de atendimento da Ouvidoria da Agência Reguladora de Serviços de Água e Esgotamento Sanitário de Minas Gerais entre os anos de 2014 e 2016. A análise dos dados demonstrou que os três indicadores conseguem fornecer informações importantes, que, ao serem analisadas juntamente com metas traçadas, poderão subsidiar as decisões do Ouvidor no sentido de aperfeiçoar a prestação do serviço com mais eficácia.
\end{abstract}

Palavras-chave: Ouvidoria. Indicadores. Ouvidor. Eficácia pública.

1 Gestora de regulação de serviços públicos. Graduada em Nutrição pela Universidade Federal dos Vales do Jequitinhonha e Mucuri. (katherynne.rodrigues@arsae.mg.gov.br) 


\begin{abstract}
The Public Ombudsman's Office is a place in which citizens can bring their needs and complaints to the attention of the Public Administration, helping them to improve their services and exercising their right to citizenship. The work carried out by the Ombudsman should be measured in order to provide efficacy, aiming at providing the highest quality service. The present study suggests three indicators that can be used in Public Ombudsman's Office: Resolubility index, Time response index and Medium time response of demands. In order to calculate the indicators, the database used by the Public Ombudsman's Office of the Agência Reguladora de Serviços de Água e Esgotamento Sanitário de Minas Gerais between 2014 and 2016 was used. Data analysis showed that all three indicators can provide important information, which, when analyzed together with goals, can support the decisions of the Ombudsman in order to improve provision of services in a more efficacy way.
\end{abstract}

Keywords: Ombudsman's Office. Indicators. Ombudsman. Public efficacy. 


\section{INTRODUÇÃO}

\section{Explanação acerca das Ouvidorias Públicas}

A democracia no Brasil se fortaleceu com a promulgação da Constituição Federal de 1988. A "Constituição Cidadã" trouxe uma ampla previsão de direitos e a institucionalização de mecanismos e processos que possibilitam a efetiva participação da sociedade na formulação, monitoramento, controle e gestão das políticas públicas (ENAP, 2015). Pode-se afirmar que a sociedade é instigada a organizar-se e apropriar-se de instrumentos como conselhos, conferências, audiências, consultas públicas, Ouvidorias, entre outros.

Dentre estes instrumentos de participação social, as Ouvidorias passaram a exercer uma função primordial na materialização do engajamento do cidadão na gestão pública. Ouvidorias Públicas são órgãos facilitadores do diálogo entre o cidadão e o Governo. Trata-se de órgãos da Administração Pública que se apresentam como instrumento autêntico da democracia participativa, dando voz ao cidadão por meio da figura do Ouvidor (MANUAL OG MG, 2015). O diálogo entre o cidadão e a Administração Pública contribui para o aperfeiçoamento dos serviços prestados.

A função principal de uma Ouvidoria é "ouvir" do cidadão sua manifestação sobre os serviços prestados, buscando a mediação de possíveis conflitos e a resolução de suas demandas (PEIXOTO; MARSIGLIA; MORRONE, 2014). Segundo RICHE (2010), a função desse "ouvir" é a de transformar a cultura de reclamação em uma cultura de cooperação e participação, garantindo assim os direitos dos cidadãos.

$\mathrm{Na}$ análise de MORAES et al. (2010), as Ouvidorias são um legítimo canal de atendimento ao cidadão, com base na neutralidade e imparcialidade. De fato, a atuação dos Ouvidores deve ser a mais neutra possível, fazendo a ponte entre o cidadão e o prestador de serviços, buscando equacionar as situações apresentadas. A instituição favorece a melhoria do serviço prestado à população possibilitando o diálogo do cidadão com a gestão participativa.

As Ouvidorias Públicas procuram realizar a interlocução dos cidadãos com o Estado, compatibilizando os princípios da democracia representativa e participativa. Segundo LACERDA (2011), as Ouvidorias buscam promover a cidadania e a defesa do cidadão quando esse não consegue ser atendido em outras instâncias inferiores. O fortalecimento do cidadão é verificado através da atuação da Ouvidoria quando ela realiza a conscientização da cidadania, aprimorando a participação social (MORAES et al., 2010).

Nesse sentido MORAES et al. (2010) escreve que:

As Ouvidorias brasileiras representam um marco nesse processo, configurando-se num espaço do ouvir dialógico, no qual a sociedade busca integração com o governo, de forma célere, responsiva e ética, certo de que será ouvida e a sua manifestação registrada, na busca da construção de um padrão de atenção ao cidadão que sofre um mal e procura o acolhimento através da escuta humanizada e a acessibilidade com resolutividade satisfatória. As manifestações recebidas pela Administração Pública são analisadas e respondidas, buscando-se a resolução da questão apresentada da melhor forma possível. 


\section{Breve relato sobre a Ouvidoria da Arsae-MG}

A Agência Reguladora de Serviços de Água e Esgotamento Sanitário de Minas Gerais (Arsae-MG) foi criada em 2009, por meio da Lei no 18.309/09. Trata-se de uma autarquia especial dotada de autonomia administrativa, financeira, técnica e patrimonial. AAgência tem por finalidade fiscalizar e orientar a prestação dos serviços públicos de abastecimento de água e de esgotamento sanitário, bem como editar normas técnicas, econômicas e sociais para a sua regulação. Tem ainda como competência supervisionar, controlar e avaliar as ações e atividades decorrentes do cumprimento da legislação específica para sua área de atuação.

A referida Lei especifica em seu corpo que a Ouvidoria faz parte da estrutura orgânica da Agência. Visando cumprir a determinação legal, a Ouvidoria da Arsae-MG foi instituída em 2009, e desde então opera como um importante canal de participação do cidadão.

O usuário possui um amplo leque de opções para entrar em contato, sendo eles o teleatendimento, o atendimento via internet, presencial, ou por carta. As demandas recebidas são classificadas como reclamação, denúncia, informação, elogio ou sugestão.

Após o recebimento, as demandas são encaminhadas aos analistas que procedem de forma a solver a questão, solicitando quando necessário apoio interno de outros setores da agência e, externo, dos prestadores de serviços regulados.

No interstício de tempo analisado, de 2014 a 2016, a Ouvidoria da Arsae-MG acolheu 3.705 demandas. As principais demandas abertas pelos usuários relacionam-se com a falta de água ou baixa pressão, o extravasamento de esgoto em via pública, o questionamento de fatura, além dos pedidos de informações diversas sobre os prestadores de serviço.

\section{A importância do uso de indicadores}

AAdministração Pública deve controlar seus próprios atos com o objetivo de aperfeiçoar a gestão e levar à melhoria do serviço público. O controle interno, exercido pelo próprio órgão, fornece informações relevantes com relação ao cumprimento das normas e à avaliação dos resultados da gestão (ENAP, 2015). Nesse contexto, os indicadores servem para monitorar informações e são formas de quantificar o trabalho executado. Os resultados obtidos podem ser disponibilizados à sociedade e utilizados para subsidiar os tomadores de decisão.

O uso de indicadores possibilita a realização de análise de desempenho, comparando o resultado obtido com a meta determinada. Dessa forma, eles são um ponto importante na melhoria contínua dos processos organizacionais (MANUAL OG MG, 2015).

Para que a Ouvidoria seja uma instituição de sucesso, é necessário que ela acolha as demandas do cidadão e facilite seu diálogo com a Administração Pública. Quantificando as ações das Ouvidorias, pode-se realizar uma análise da eficiência, eficácia e efetividade e assim observar se o papel que lhes foi imposto está sendo cumprido. Dessa forma, usar esses indicadores pode permitir que o gestor público conheça seus resultados e trace novas metas de trabalho, de forma a atingir seus objetivos (GRATERON, 1991). 
O presente trabalho tem por objetivo a sugestão de indicadores que possam ser utilizados pela Ouvidoria da Arsae-MG, de forma a aprimorar a gestão e a tomada de decisão.

\section{DESENVOLVIMENTO}

Os dados trabalhados foram coletados nos arquivos de atendimento da Ouvidoria da Arsae-MG.

A equipe gera mensalmente tabelas contendo todos os dados de atendimento classificados em: número de protocolo, canal de atendimento, nome, data de abertura, bairro, município, prestador, natureza, detalhamento e data de encerramento. Os dados foram agrupados por ano como forma de divisão para efeitos de cálculo dos indicadores.

A amostra não é probabilística, foi selecionada segundo critérios de conveniência do pesquisador visto que desde 2009 a metodologia de trabalho sofreu grandes ajustes. Desse modo, optou-se por analisar os últimos três anos (2014 a 2016), pois nestes a forma de tratamento das demandas foi semelhante.

De acordo com MANUAL OG MG (2015), uma das finalidades das Ouvidorias Públicas é a formação de diagnósticos visando uma ação qualitativa de melhoria da prestação dos serviços. Para elaborar tais diagnósticos faz-se necessário mensurar as manifestações recebidas por meio dos canais de atendimento das Ouvidorias. É nessa etapa que fica visível a importância do uso de indicadores adequados.

Segundo SOUZA JUNIOR (2011), os indicadores podem ser classificados em estratégicos, de produtividade (eficiência), de qualidade (eficácia), de efetividade (impacto) e de capacidade. É preciso, porém, discernimento na escolha de tais indicadores, verificando se o escolhido de fato refletirá o ponto desejado.

Ao gestor que faz uso de indicadores adequados é possibilitado o conhecimento do passado e do momento atual, além de fornecer um direcionamento do futuro. Por conseguinte, um indicador deve oferecer informações que possibilitem a tomada de decisões, no sentido de melhorar o serviço efetuado. Deve ainda ser confiável, acessível e de baixo custo (SOUZA JUNIOR, 2011).

As principais qualidades de um indicador segundo GRATERON (1991) são: relevância, pertinência, objetividade, sensibilidade, precisão e um bom custo-benefício.

LACERDA (2011) entende que os indicadores possibilitam ao Ouvidor o controle e a avaliação dos processos da Ouvidoria. Os indicadores permitem observar o alcance das metas contribuindo para a melhoria contínua dos processos organizacionais, além de auxiliar no processo de tomada de decisões (MINISTÉRIO DA SAÚDE, 2013).

Após estudos iniciais, chegou-se a três indicadores que são recomendados para uso pela Ouvidoria da Arsae-MG: Índice de resolubilidade, Índice de atendimento aos prazos de resposta e Prazo médio de resposta das demandas. Ver Tabela 1. 


\section{TABELA 1 - Indicadores Sugeridos: conceitos e fórmulas}

\begin{tabular}{|c|c|c|}
\hline INDICADORES & CONCEITO DOS INDICADORES & FÓRMULA DOS INDICADORES \\
\hline $\begin{array}{l}\text { Índice de } \\
\text { resolubilidade }\end{array}$ & $\begin{array}{l}\text { O indicador mensura o percentual } \\
\text { de manifestações resolvidas com a } \\
\text { intervenção da Ouvidoria. }\end{array}$ & $\frac{N^{\circ} \text { de manifestações resolvidas }}{N^{\circ} \text { total de manifestações recebidas }} \times 100$ \\
\hline $\begin{array}{l}\text { Índice de } \\
\text { atendimento aos } \\
\text { prazos de resposta }\end{array}$ & $\begin{array}{l}\text { O indicador representa a quanti- } \\
\text { dade de respostas, encaminhadas } \\
\text { pela Ouvidoria ao cidadão-usuário, } \\
\text { dentro do prazo de } 10 \text { dias. }\end{array}$ & $\frac{N^{0} \text { de manifestações encerradas em até } 10 \text { dias }}{N^{\circ} \text { total de manifestações }} \times 100$ \\
\hline $\begin{array}{l}\text { Prazo médio de } \\
\text { respostas das } \\
\text { demandas }\end{array}$ & $\begin{array}{l}\text { O indicador representa o tempo } \\
\text { médio de encaminhamento de } \\
\text { respostas ao usuário, a partir do } \\
\text { recebimento da demanda. }\end{array}$ & $\begin{array}{l}\text { Média da data de resposta ao cidadão (-) Data de } \\
\text { registro da manifestação }\end{array}$ \\
\hline
\end{tabular}

O Gráfico 1 demostra o número de demandas que foram efetivamente trabalhadas pela Ouvidoria da Arsae-MG. Nesse total, estão as demandas nas quais a Ouvidoria atuou visando a solucionar os problemas trazidos pelo cidadão. No total anual não entram os pedidos de informação que foram prestadas diretamente pelos atendentes, sem que fosse necessária uma atuação efetiva dos analistas.

\section{GRÁFICO 1 - Número absoluto de demandas trabalhadas pela Ouvidoria da Arsae-MG entre 2014 e 2016}

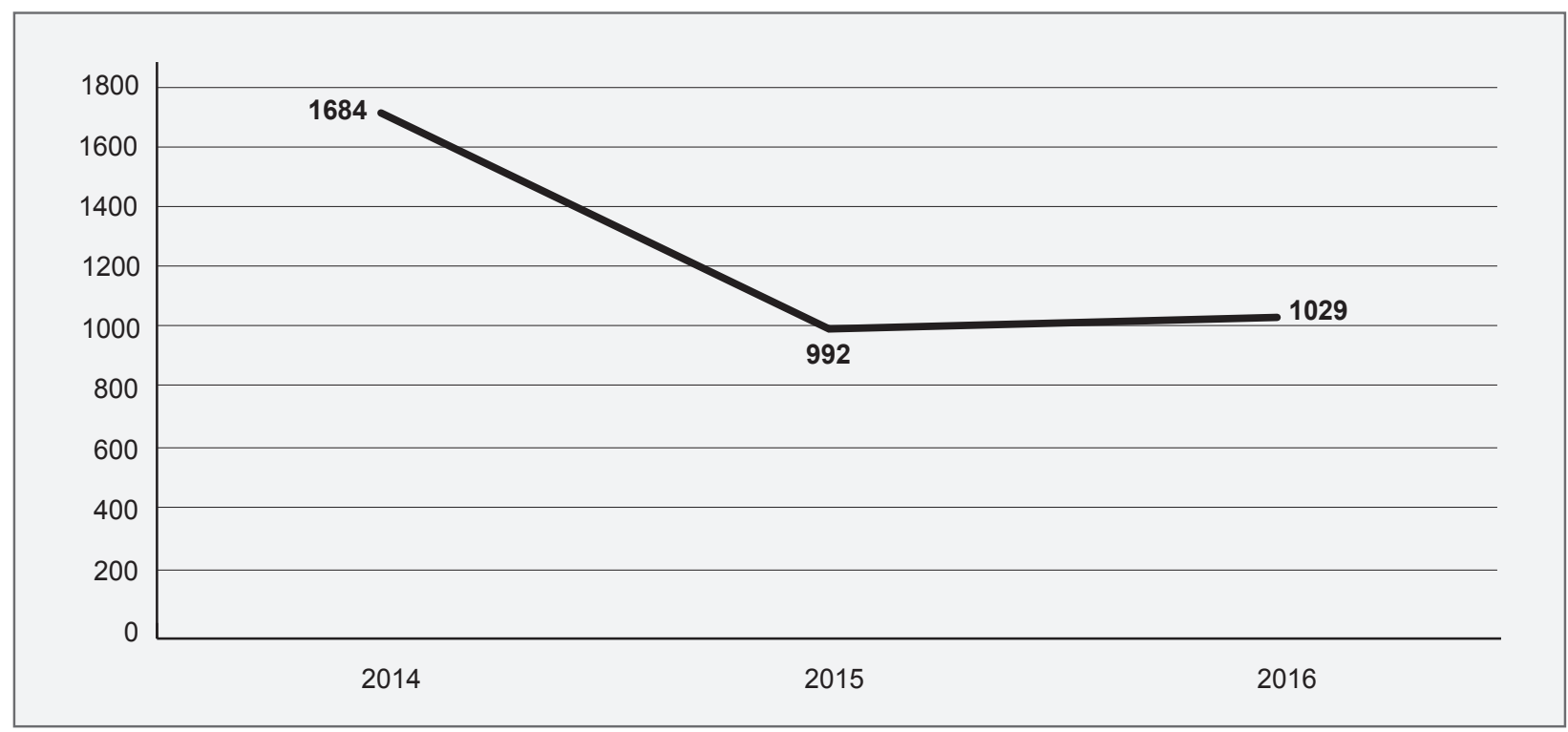

Trabalhando-se os dados de atendimento da Ouvidoria da Arsae-MG dos últimos três anos, de acordo com as fórmulas dos indicadores, os resultados obtidos foram os demonstrados na Tabela 2. 


\section{TABELA 2 - Cálculo Anual dos Indicadores}

\begin{tabular}{|l|l|l|l|}
\hline ANO & $\begin{array}{l}\text { ÍNDICE DE } \\
\text { RESOLUBILIDADE }\end{array}$ & $\begin{array}{l}\text { ÍNDICE DE ATENDIMENTO } \\
\text { AOS PRAZOS DE RESPOSTA }\end{array}$ & $\begin{array}{l}\text { PRAZO MÉDIO DE RESPOSTA } \\
\text { DAS DEMANDAS }\end{array}$ \\
\hline $\mathbf{2 0 1 4}$ & $97,51 \%$ & $93,45 \%$ & 3,28 dias \\
\hline $\mathbf{2 0 1 5}$ & $98,49 \%$ & $86,99 \%$ & 5,47 dias \\
\hline $\mathbf{2 0 1 6}$ & $97,96 \%$ & $78,52 \%$ & 6,74 dias \\
\hline
\end{tabular}

Ao efetuar a análise dos resultados ano a ano, percebe-se que a Ouvidoria da Arsae-MG cumpre seu papel social de dar voz ao cidadão e solucionar as questões apresentadas. O Índice de resolubilidade indicou que mais de $97 \%$ das demandas recebidas foram solucionadas dentro do mesmo ano em que foram abertas.

O segundo indicador monitorado mostra o percentual de encerramento de demandas em até 10 dias após o seu acolhimento pela Ouvidoria. O índice aponta uma queda, demonstrando que as demandas estão consumindo um número maior de dias para a sua conclusão, o que enseja do gestor um cuidado maior com esse indicador.

Já o prazo médio de resposta das demandas demonstra a média de dias em que o usuário recebe a solução do seu problema. Como a Ouvidoria busca encerrar as demandas em até 10 dias após o seu recebimento, o prazo médio de 6,74 indica que a maioria das demandas está sendo fechada antes do prazo proposto.

Após a escolha dos indicadores faz-se necessário definir metas que servirão de balizamento para a conduta da equipe de trabalho. As metas devem ser realistas e alcançáveis de forma a se evitar situações estressantes e frustrantes que causem a desmotivação dos funcionários. Por outro lado, as metas não devem ser facilmente atingíveis, evitando-se a acomodação.

Consoante o MINISTÉRIO DA SAÚDE (2013), as metas demonstram um compromisso da equipe para alcançar determinado objetivo. Ao se comparar as metas com o resultado dos indicadores pode-se medir a eficácia do trabalho da equipe. Esta é a medida do grau de cumprimento dos objetivos e metas fixados, ou seja, a comparação entre os resultados obtidos e os resultados esperados (GRATERON, 1991).

\section{CONSIDERAÇÕES}

As Ouvidorias Públicas possuem um papel crucial na defesa dos cidadãos junto ao Estado, atuando como instituição de controle e participação social. Por intermédio das Ouvidorias, a sociedade possui um canal para buscar informações, realizar denúncias, registrar reclamações, sugerir e elogiar o serviço público recebido. 
O uso de indicadores que contemplem as atividades realizadas pela equipe da Ouvidoria é fundamental para balizar o trabalho do Ouvidor. Com os indicadores definidos, pode-se estabelecer metas que, após o decurso do tempo, refletirão a eficácia da Ouvidoria.

O Índice de resolubilidade, o Índice de atendimento aos prazos de resposta e o Prazo médio de respostas das demandas são indicadores aconselháveis para uso na Ouvidoria da Arsae-MG, uma vez que são de fácil obtenção e monitoramento, além de refletirem de forma clara o trabalho da equipe.

Pautar o trabalho da equipe em metas plausíveis estimula a melhoria dos serviços públicos prestados e a promoção dos direitos humanos, pois a Administração Pública necessita estar constantemente aberta para receber o cidadão e buscar ofertar os serviços da melhor forma possível. Portanto, uma Ouvidoria que atue observando indicadores e com metas definidas estará dando um passo à frente no aprimoramento da gestão pública.

\section{REFERÊNCIAS}

ENAP. Controle Social. Brasília, DF. 2015. Disponível em: <https://enapvirtual.enap.gov.br/mod/folder/view. php?id=52657>. Acesso em: 06 jun. 2017.

GOVERNO DE MINAS - OUVIDORIA-GERAL. Ouvidoria Pública Passo a Passo: Manual de criação, aperfeiçoamento e boas práticas. MG. 2015. Disponível em: <http://fnou.com.br/mwginternal/de5fs23hu73ds/progress?id=lFRE7p7gLAIC_e3p8kcnmdZkcLFqEv8OFQA790-Xoos>. Acesso em: 05 jan. 2017.

GRATERON, Ivan Ricardo Guevara. Auditoria de gestão: utilização de indicadores de gestão no setor público. Caderno de estudos, n. 21, p. 01-18, 1999. Disponível em: <http://www.scielo.br/scielo.php?script=sci_arttext\&pi$\mathrm{d}=\mathrm{S} 1413-92511999000200002 \& \mathrm{Ing}=\mathrm{en} \& \mathrm{nrm}=\mathrm{iso}>$. Acesso em: 20 nov. 2014.

LACERDA, Ricardo. Ouvidoria: Portal da Cidadania. 2. ed rev. e ampl. Olinda, PE: Livro Rápido, 2011. p. 89

BRASIL. Lei $n^{\circ}$ 18.309/09, de 03 de agosto de 2009. Disponível em: <http://www.almg.gov.br/consulte/legislacao/ completa/completa.html?tipo=LEI\&num=18309\&ano=2009> Acesso em: 24 jan. 2017.

MINISTÉRIO DA SAÚDE. Caderno de Diretrizes, Objetivos, Metas e Indicadores - 2013/2015. Brasília, DF. 2013. Disponível em: <http://bvsms.saude.gov.br/bvs/publicacoes/caderno_diretrizes_objetivos_2013_2015.pdf>. Acesso em: 05 jan. 2017

MORAES, Diana; CRUZ, Amanda; SILVEIRA, Flávia; FERLA, Alcindo. A Ouvidoria como um processo democrático: sua história e experiência no Pará. Belém, PA. 2010. Disponível em: <http://www.sead.pa.gov.br/sites/default/files/ ouvidoriacomoprocessodemocraticohistoriadasouvidorias.pdf> Acesso em: 15 dez. 2016.

PEIXOTO, Stefano Frugoli; MARSIGLIA, Regina Maria Giffoni; MORRONE, Luiz Carlos. Atribuições de uma Ouvidoria: opinião de usuários e funcionários. Saúde soc., São Paulo, v. 22, n. 3, 2013. Disponível em: <http://www.scielo. br/scielo.php?script=sci_arttext\&pid=S0104-12902013000300012\&Ing=pt\&nrm=iso>. Acesso em: 12 nov. 2014.

RICHE, Cristina Ayoub. Ouvidoria, caminho para a civilidade e diálogo. Organicom. São Paulo, ano 7, n. 12, p. 180$182,2010$.

SOUZA JUNIOR, Geraldo Lopes de. Elaboração e Análise de Indicadores. AM. 2011. Disponível em: <http://livrozilla. com/doc/774067/elabora\%C3\%A7\%C3\%A3o-e-an\%C3\%A1lise-de-indicadores>. Acesso em: 10 jan. 2017. 